Arq. Bras. Med. Vet. Zootec., v.68, n.1, p.155-163, 2016

\title{
Níveis séricos e hepáticos de cobre, zinco, ferro e molibdênio em ovinos e caprinos criados no semiárido da Bahia
}

\author{
[Serum and hepatic levels of copper, zinc, iron and molybdenum in sheep and goats \\ raised in the semiarid of Bahia state] \\ W.R. Silva ${ }^{1}$, I.M.M. Gomes ${ }^{2}$, J.F. Rocha Filho ${ }^{2}$, C.S. Mori ${ }^{3}$, L.E.S. Michima ${ }^{3}$, \\ E.L. Ortolani ${ }^{3}$, A.C. Antonelli ${ }^{4 *}$

\footnotetext{
${ }^{1}$ Aluno de pós-graduação - Universidade Federal do Vale do São Francisco - Univasf - Petrolina, PE

${ }^{2}$ Aluno de graduação - Universidade Federal do Vale do São Francisco - Univasf - Petrolina, PE

${ }^{4}$ Universidade Federal do Vale do São Francisco - Univasf - Petrolina, PE
} \\ ${ }^{3}$ Faculdade de Medicina Veterinária e Zootecnia - Universidade de São Paulo - FMVZ/USP - São Paulo, SP
}

\begin{abstract}
RESUMO
Objetivou-se conhecer os teores de cobre, zinco, ferro e molibdênio em soro e fígado de pequenos ruminantes criados nos municípios de Casa Nova e Juazeiro, estado da Bahia, e verificar se há carência primária ou secundária de cobre. Foi avaliado um total de 160 amostras de ovinos e caprinos de ambos os sexos, coletados nos períodos seco e chuvoso. O valor de cobre sérico para caprinos foi de $13,8 \pm 0,3 \mu \mathrm{mol} / \mathrm{L}$ e para ovinos foi de $12,2 \pm 0,4 \mu \mathrm{mol} / \mathrm{L}$, enquanto os teores hepáticos médios foram de $220 \mathrm{ppm}$ para caprinos e $238 \mathrm{ppm}$ para ovinos. O valor de zinco sérico para caprinos foi de $28,3 \pm 1,0 \mu \mathrm{mol} / \mathrm{L}$ e para ovinos foi de $28,7 \pm 0,8 \mu \mathrm{mol} / \mathrm{L}$, enquanto os teores hepáticos médios foram de 99ppm para caprinos e 92ppm para ovinos. O valor de ferro sérico para caprinos foi de $61 \pm 3 \mu \mathrm{mol} / \mathrm{L}$ e para ovinos foi de $64 \pm 2 \mu \mathrm{mol} / \mathrm{L}$, enquanto os teores hepáticos foram de $172 \mathrm{ppm}$ para caprinos e $221 \mathrm{ppm}$ para ovinos. Os valores médios de cobre não indicam ocorrência de carência deste elemento nos pequenos ruminantes criados nos municípios estudados. Os teores de zinco encontravam-se dentro dos intervalos de normalidade, não sendo verificada a necessidade de suplementação extra deste mineral. Os teores de ferro sérico apresentavam-se bem elevados, contudo sem que houvesse interferência suficiente no metabolismo do cobre de forma a resultar em uma deficiência cúprica.
\end{abstract}

Palavras-chave: microminerais, fígado, soro, pequenos ruminantes

\begin{abstract}
The aim of this research was to know the copper, zinc, iron and molybdenum content in serum and liver of small ruminants raised in the cities of Casa Nova and Juazeiro, state of Bahia, and verify the occurrence of primary or secondary copper deficiency. A total of 160 samples of sheep and goats of both sexes collected in the dry and rainy season were evaluated. The values for serum copper in goats was $13.8 \pm 0.3 \mu \mathrm{mol} / \mathrm{L}$ and in sheep it was $12.2 \pm 0.4 \mu \mathrm{mol} / \mathrm{L}$, while the mean liver concentration was $220 \mathrm{ppm}$ for goats and $238 \mathrm{ppm}$ for sheep. The serum zinc value for goats was $28.3 \pm 1.0 \mu \mathrm{mol} / \mathrm{L}$ and for sheep it was $28.7 \pm 0.8 \mu \mathrm{mol} / \mathrm{L}$, while the mean liver concentration was $99 \mathrm{ppm}$ for goats and $92 \mathrm{ppm}$ for sheep. Serum iron value for goats was $61 \pm 3 \mu \mathrm{mol} / \mathrm{L}$ and for sheep it was $64 \pm 2 \mu \mathrm{mol} / \mathrm{L}$, while liver levels were 172 ppm for goats and 221 ppm for sheep. Copper mean values do not indicate the occurrence of copper deficiency in small ruminants raised in the cities studied. Zinc levels were within the normal values and do not require extra supplementation of this mineral. The serum iron levels were elevated, however it did not interfere in copper metabolism in order to result in a cupric deficiency.
\end{abstract}

Keywords: microminerals, liver, serum, small ruminants

Recebido em 19 de maio de 2015

Aceito em 16 de setembro de 2015

*Autor para correspondência (corresponding author)

E-mail: alexandre.antonelli@univasf.edu.br 


\section{INTRODUÇÃO}

Dos diversos estudos sobre as carências minerais em ruminantes, bem como sobre as formas de suplementação mais eficientes e econômicas, a maior parte dos trabalhos foi conduzida com bovinos. As informações sobre as deficiências minerais em ovinos e caprinos são limitadas, principalmente em relação a caprinos e àqueles criados na região semiárida (McDowell, 1999; Tokarnia et al., 2000).

A falta de estudos faz com que criadores suplementem os animais com minerais que não são necessários e, inclusive, atuem como antagonistas para outros minerais, como, por exemplo, o molibdênio, que antagoniza o cobre; o ferro, que antagoniza o fósforo e o cobre; e o enxofre, que antagoniza o cobre e o selênio (McDowell, 1999; Tokarnia et al., 1999).

Poucos são os estudos realizados no estado da Bahia relacionados à carência de cobre em pequenos ruminantes, principalmente na região do semiárido, onde se concentra grande parte dos caprinos e ovinos, que se adaptaram às características da região. Atualmente, a Bahia tem o maior rebanho tanto de caprinos quanto de ovinos do país com 4,2 e 2,5 milhões de cabeças, o que representa $42,0 \%$ e $16,5 \%$ do rebanho nacional, respectivamente. A microrregião geográfica de Juazeiro-BA (mesorregião Vale São-Franciscano da Bahia) destaca-se como uma das principais produtoras de caprinos e ovinos. Outro fato importante é que $50 \%$ do rebanho de caprinos e ovinos do Nordeste estão localizados em propriedades com menos de $30 \mathrm{ha}$, exploradas em sistema extensivo, onde não são adotadas práticas adequadas de manejo alimentar e sanitário, contribuindo para a baixa produtividade da ovinocaprinocultura (BRASIL, 2006).

Assim, objetivou-se conhecer os teores de cobre e de seus principais antagonistas (molibdênio, ferro e zinco) no sangue e fígado de ovinos e caprinos e no solo, nas propriedades das cidades de Juazeiro e Casa Nova do estado da Bahia, considerando-se a espécie, o sexo e a sazonalidade.

\section{MATERIAL E MÉTODOS}

O presente estudo foi aprovado pelo Comitê de Ética e Deontologia em Estudos e Pesquisas (protocolo $\mathrm{n}^{\mathrm{o}}$ 0019/041011-Cedep) da Universidade Federal do Vale do São Francisco.

Este trabalho foi conduzido no Abatedouro Almeida Ltda. (Abatal), localizado no município de Juazeiro, Bahia, Brasil ( $9^{\circ} 25^{\prime} 48.90^{\prime \prime} \mathrm{S} ; 40^{\circ}$ $28^{\prime} 13.25^{\prime \prime} \mathrm{O}$ ). No abatedouro, os animais foram escolhidos aleatoriamente dentro de lotes pelo médico veterinário responsável pelo Serviço de Inspeção Sanitária do estabelecimento, conforme o município de procedência do animal, sendo selecionados apenas animais oriundos dos municípios de Juazeiro e Casa Nova, ambos contidos na microrregião de Juazeiro, situado na mesorregião do Vale São-Franciscano da Bahia.

Foram selecionados 80 caprinos e 80 ovinos, sendo divididos em dois grupos iguais (20 machos e 20 fêmeas de cada espécie), de acordo com os períodos (chuvoso e seco), totalizando, ao final do experimento, 160 animais.

Para se definirem os períodos seco e chuvoso na microrregião de Juazeiro, foram utilizados os registros de dados históricos de precipitação pluviométrica junto ao Instituto Nacional de Meteorologia (INMET), definidos pela média histórica para a região. Considerando-se a média histórica da pluviosidade para os municípios da microrregião de Juazeiro, estabeleceu-se o terço final do período chuvoso nos meses de março e abril e o terço final do período seco nos meses de agosto e setembro. Dessa forma, procedeu-se a toda a coleta de material biológico no abatedouro nos períodos de agosto e setembro de 2013 e março e abril de 2014.

Amostras de sangue foram coletadas por venopunção da veia jugular em tubos siliconizados para coleta a vácuo sem anticoagulante para obtenção de soro, utilizandose agulha $25 \times 8$. As coletas de sangue foram realizadas durante o período de descanso préabate, com os animais em jejum por um período médio de seis horas. As amostras foram centrifugadas e armazenadas a $-20^{\circ} \mathrm{C}$ até serem processadas. 
As amostras de fígado foram obtidas após o abate dos animais, no momento da evisceração deles pelos funcionários do abatedouro, sendo coletadas por meio de corte no lóbulo caudal do fígado, obtendo-se uma amostra de cerca de $50 \mathrm{~g}$. Os fragmentos eram secos com papel-filtro para retirada do excesso de sangue e armazenados em coletores universais de $50 \mathrm{~mL}$, devidamente identificados, e armazenados a $-20^{\circ} \mathrm{C}$ até serem processados.

As amostras de soro e fígado foram digeridas, e os teores séricos e hepáticos de cobre, zinco, ferro e molibdênio determinados por meio de espectrometria óptica por emissão de plasma, de acordo com protocolo descrito por Minervino (2011).

Após a coleta de material biológico, realizou-se o rastreamento dos animais, buscando-se identificar as propriedades de origem deles. Com base nessa informação, foram realizadas visitas às propriedades para coletar amostras de solo e caracterizar os sistemas de produção e manejo dos animais. Para obter essas informações, foram aplicados questionários aos proprietários. Foi coletado material de animais oriundos de 13 fazendas das duas cidades durante todo o experimento, sendo seis propriedades localizadas no município de Casa Nova e sete no município de Juazeiro.

As amostras de solo foram coletadas e analisadas pelo método de extração com solução de Mehlich 1 para determinação de cobre, zinco e ferro (Page et al., 1986; Silva, 2009). Os teores médios de cobre foram de $0,90 \pm 0,10 \mathrm{mg} / \mathrm{dm}^{3}$, enquanto os teores médios de zinco determinados foram de $148 \pm 16,1 \mathrm{mg} / \mathrm{dm}^{3}$, e os teores médios de ferro no solo foram de $46,9 \pm 7,8 \mathrm{mg} / \mathrm{dm}^{3}$. O pH médio do solo foi de 6,75 .

Os dados obtidos foram primeiramente analisados quanto a sua distribuição normal pela prova de Kolmogorov-Smirnov, em que todas as variáveis apresentaram distribuição normal. Posteriormente, esses dados foram avaliados segundo testes estatísticos paramétricos, por meio de análise de variância, separando-se como fonte de variação o efeito das espécies, do sexo e do período. Foi avaliada também a variação do período separadamente por espécie. $\mathrm{O}$ modelo matemático utilizado foi: $\mathrm{Y}_{\mathrm{ij}}=\mathrm{E}+\mathrm{S}+\mathrm{P}+\mathrm{ESP}+$ $e_{i j}$, em que: $Y_{i j}=$ valor observado; $E=$ efeito da espécie; $\mathrm{S}=$ efeito do sexo; $\mathrm{P}=$ efeito do período; $\mathrm{ESP}=$ interação espécie $\mathrm{x}$ sexo $\mathrm{x}$ período; $\mathrm{e}_{\mathrm{ij}}=$ erro. Para a análise separada por espécie, foi utilizado o modelo: $\mathrm{Y}_{\mathrm{ij}}=\mathrm{S}+\mathrm{P}+\mathrm{e}_{\mathrm{ij}}$, em que: $\mathrm{Y}_{\mathrm{ij}}=$ valor observado; $\mathrm{S}=$ efeito do sexo; $\mathrm{P}=$ efeito do período; $\mathrm{e}_{\mathrm{ij}}=$ erro. Não foi analisada a interação entre as fontes de variação, sendo realizada a análise de variância testando apenas os efeitos principais. Quando os efeitos principais foram significativos no teste $F$, as médias foram confrontadas pelo teste de TukeyKramer. Foi adotado o nível de significância de $5 \%(\mathrm{P} \leq 0,05)$ para todas as análises realizadas.

\section{RESULTADOS}

Em relação ao cobre sérico, foi verificada a existência de diferença significativa apenas para espécie e sexo. A variável zinco sérico não mostrou diferença significativa. $\mathrm{O}$ ferro sérico demonstrou diferença significativa para período. Ao se analisarem os resultados do molibdênio sérico, foi possível verificar que houve diferença significativa para período, espécie e sexo.

Quando comparadas as médias de cobre sérico para espécie, constatou-se que os caprinos apresentaram um valor significativamente superior aos ovinos, e, para a variação sexo, verificou-se que fêmeas mostraram valores significativamente mais elevados que machos, conforme se pode constatar na Tab. 1.

Ao se analisarem os resultados referentes aos teores séricos de ferro, foi possível verificar que, durante o período chuvoso, os animais apresentaram um valor significativamente superior aos animais abatidos durante o período seco, como mostra a Tab. 1.

Ao serem analisados os resultados do molibdênio sérico, foi possível verificar que os animais criados no período chuvoso apresentavam valores significativamente superiores aos animais do período seco. Já ao se compararem as espécies, foram determinados nos ovinos valores significativamente maiores que nos caprinos. E quando avaliada a variação em relação ao sexo dos pequenos ruminantes, os machos possuíam valores significativamente superiores aos valores médios apresentados pelas fêmeas, conforme demonstrado na Tab. 1. 
Tabela 1. Valores médios e erro-padrão das médias dos teores de cobre, zinco, ferro e molibdênio sérico $(\mu \mathrm{mol} / \mathrm{L})$ de ovinos e caprinos criados na região semiárida da Bahia por período, espécie e sexo e por período separadamente por espécie

\begin{tabular}{|c|c|c|c|c|c|c|}
\hline \multirow{2}{*}{ Variáveis } & \multicolumn{2}{|c|}{ Período } & \multicolumn{2}{|c|}{ Espécie } & \multicolumn{2}{|c|}{ Sexo } \\
\hline & Seco & Chuvoso & Ovino & Caprino & Macho & Fêmea \\
\hline Cobre & $12,9 \pm 0,4$ & $13,2 \pm 0,4$ & $12,2 \pm 0,4 \mathrm{~B}$ & $13,8 \pm 0,3 \mathrm{~A}$ & $12,2 \pm 0,3 \mathrm{~B}$ & $13,8 \pm 0,4 \mathrm{~A}$ \\
\hline Zinco & $27,3 \pm 1,1$ & $29,7 \pm 0,7$ & $28,7 \pm 0,8$ & $28,3 \pm 1,0$ & $28,7 \pm 0,8$ & $28,3 \pm 1,0$ \\
\hline Ferro & $50 \pm 2 \mathrm{~B}$ & $73 \pm 2 \mathrm{~A}$ & $64 \pm 2$ & $61 \pm 3$ & $64 \pm 2$ & $60 \pm 3$ \\
\hline \multirow[t]{3}{*}{ Molibdênio } & $0,16 \pm 0,02$ & $0,26 \pm 0,02 \mathrm{~A}$ & $0,25 \pm 0,02$ & $0,19 \pm 0,02 \mathrm{~B}$ & $0,24 \pm 0,02$ & $0,19 \pm 0,02 \mathrm{~B}$ \\
\hline & \multicolumn{3}{|c|}{ Ovino } & \multicolumn{3}{|c|}{ Caprino } \\
\hline & Seco & \multicolumn{2}{|c|}{ Chuvoso } & Seco & \multicolumn{2}{|c|}{ Chuvoso } \\
\hline Cobre & $12,3 \pm 0,6$ & \multicolumn{2}{|c|}{$12,2 \pm 0,5$} & $13,4 \pm 0,5$ & \multicolumn{2}{|c|}{$14,1 \pm 0,4$} \\
\hline Zinco & $27,1 \pm 1,4$ & \multicolumn{2}{|c|}{$30,4 \pm 0,7$} & $27,4 \pm 1,6$ & \multicolumn{2}{|c|}{$28,2 \pm 1,2$} \\
\hline Ferro & \multirow{2}{*}{$\begin{array}{c}54,6 \pm 3,3 \\
0,19 \pm 0,03\end{array}$} & \multicolumn{2}{|c|}{$72,6 \pm 3,1$} & $47,2 \pm 2,2$ & \multicolumn{2}{|c|}{$75,0 \pm 3,5$} \\
\hline Molibdênio & & \multicolumn{2}{|c|}{$0,29 \pm 0,03$} & $0,13 \pm 0,02$ & \multicolumn{2}{|c|}{$0,24 \pm 0,02$} \\
\hline
\end{tabular}

Nota: Letras maiúsculas distintas nas linhas indicam diferenças significativas dentro de cada fator $(\mathrm{P}<0,05)$.

Quando avaliados os teores hepáticos dos microminerais, foi verificado que não existiu diferença significativa em relação ao cobre hepático. O zinco hepático mostrou diferença significativa para período e sexo e para o período separadamente por espécie. Já o ferro hepático mostrou diferença significativa para período e espécie e para o período separadamente por espécie, para ovinos. Ao se analisarem os resultados do molibdênio hepático, foi possível verificar que houve diferença significativa para sexo e para o período separadamente por espécie, para ovinos.

Quando analisados os valores hepáticos de zinco, verificou-se que não houve variação significativa entre ovinos e caprinos, assim como não houve diferença significativa entre machos e fêmeas. No entanto, os animais do período chuvoso apresentaram valores significativamente mais elevados que os animais do período seco. Já quando comparados os resultados do período separadamente por espécie, verificou-se que tanto os ovinos do período chuvoso quanto os caprinos do período chuvoso apresentaram os maiores valores significativos em relação aos de suas espécies no período seco, conforme demonstrado na Tab. 2.
Os resultados de ferro hepático mostram que não houve variação significativa entre machos e fêmeas, contudo os animais do período chuvoso apresentaram valores significativamente superiores aos animais do período seco, assim como os ovinos também obtiveram médias significativamente maiores que os caprinos. Ao se analisar a variação por período separadamente por espécie, verificou-se variação apenas para os ovinos, a qual consistiu em que os animais do período chuvoso apresentaram valores significativamente mais elevados que os ovinos do período seco, como apresentado na Tab. 2.

Ao serem avaliados os resultados do molibdênio hepático, verificou-se que as fêmeas apresentaram valores significativamente superiores aos machos e que não houve diferença entre o período seco e o chuvoso, assim como entre os caprinos e os ovinos. Ao se avaliar a variação no período por espécie, foi possível verificar que os ovinos do período chuvoso apresentaram teor hepático de molibdênio significativamente mais elevado que os ovinos do período seco e que não houve variação entre os períodos para os caprinos, conforme mostra a Tab. 2. 
Tabela 2. Valores médios e erro-padrão das médias dos teores de cobre, zinco, ferro e molibdênio hepático (ppm) de ovinos e caprinos criados na região semiárida da Bahia por período, espécie e sexo e por período separadamente por espécie

\begin{tabular}{|c|c|c|c|c|c|c|}
\hline \multirow{2}{*}{ Variáveis } & \multicolumn{2}{|c|}{ Período } & \multicolumn{2}{|c|}{ Espécie } & \multicolumn{2}{|c|}{ Sexo } \\
\hline & Seco & Chuvoso & Ovino & Caprino & Macho & Fêmea \\
\hline Cobre & $219 \pm 14$ & $239 \pm 14$ & $238 \pm 14$ & $220 \pm 13$ & $234 \pm 15$ & $224 \pm 13$ \\
\hline Zinco & $74 \pm 5 B$ & $116 \pm 3 \mathrm{~A}$ & $92 \pm 5$ & $99 \pm 4$ & $90 \pm 5 B$ & $100 \pm 4 \mathrm{~A}$ \\
\hline Ferro & $178 \pm 15 B$ & $215 \pm 11 \mathrm{~A}$ & $221 \pm 16 \mathrm{~A}$ & $172 \pm 10 \mathrm{~B}$ & $185 \pm 12$ & $208 \pm 15$ \\
\hline \multirow[t]{3}{*}{ Molibdênio } & $2,5 \pm 0,2$ & $2,5 \pm 0,1$ & $2,5 \pm 0,1$ & $2,5 \pm 0,2$ & $2,1 \pm 0,1 \mathrm{~B}$ & $2,8 \pm 0,2 \mathrm{~A}$ \\
\hline & \multicolumn{3}{|c|}{ Ovino } & \multicolumn{3}{|c|}{ Caprino } \\
\hline & \multicolumn{2}{|l|}{ Seco } & Chuvoso & Seco & \multicolumn{2}{|r|}{ Chuvoso } \\
\hline Cobre & \multicolumn{2}{|l|}{$243 \pm 23$} & $233 \pm 18$ & $195 \pm 16$ & \multicolumn{2}{|r|}{$246 \pm 21$} \\
\hline Zinco & \multicolumn{2}{|l|}{$63 \pm 5 B$} & $120 \pm 6 \mathrm{~A}$ & $85 \pm 7 \mathrm{~B}$ & \multicolumn{2}{|r|}{$112 \pm 3 \mathrm{~A}$} \\
\hline Ferro & \multicolumn{2}{|l|}{$176 \pm 25 B$} & $269 \pm 16 \mathrm{~A}$ & $181 \pm 18$ & \multicolumn{2}{|r|}{$164 \pm 8$} \\
\hline Molibdênio & \multicolumn{2}{|l|}{$2,2 \pm 0,2 \mathrm{~B}$} & $2,8 \pm 0,2 \mathrm{~A}$ & $2,7 \pm 0,3$ & \multicolumn{2}{|r|}{$2,2 \pm 0,2$} \\
\hline
\end{tabular}

Nota: Letras maiúsculas distintas nas linhas indicam diferenças significativas dentro de cada fonte de variação $(\mathrm{P}<0,05)$.

\section{DISCUSSÃO}

$\mathrm{Na}$ região estudada, a figura do atravessador é marcante. Neste experimento, todos os animais utilizados, apesar de oriundos de 13 propriedades diferentes, foram comercializados com o abatedouro por meio de um atravessador, impossibilitando relacionar diretamente o animal a sua propriedade de origem, pois o atravessador compra animais de diversas propriedades e os leva ao abatedouro em um lote único. Esse relacionamento elevado com atravessadores foi verificado também no município de Tauá-CE, terceiro maior município criador de ovinos no Nordeste e onde $73,5 \%$ dos proprietários afirmam comercializar seus animais com atravessadores (Belchior et al., 2014). Esse fato justifica a dificuldade neste estudo em realizar uma análise mais profunda da influência dos teores de microminerais no solo e sua relação com suas concentrações nos tecidos biológicos dos animais.

É possível, entretanto, fazer algumas considerações sobre os solos analisados. Os valores médios de cobre de $0,9 \mathrm{mg} / \mathrm{dm}^{3}$ são considerados como apresentando teores médios de cobre segundo Ribeiro et al. (1999). Já segundo Sousa et al. (1980), esses valores são próximos aos considerados deficientes $\left(<0,6 \mathrm{mg} / \mathrm{dm}^{3}\right)$, estando abaixo do considerado normal $\left(2 \mathrm{mg} / \mathrm{dm}^{3}\right)$. Em relação ao ferro no solo, os teores médios de $46,9 \mathrm{mg} / \mathrm{dm}^{3}$ são considerados de alta disponibilidade segundo Ribeiro et al. (1999), assim como os teores médios de zinco $\left(148 \mathrm{mg} / \mathrm{dm}^{3}\right)$.

A solubilidade de microminerais catiônicos no solo, como cobre, zinco e ferro, diminui conforme o $\mathrm{pH}$ do solo vai ficando mais alcalino, segundo demonstrou Camargo et al. (1982). E quanto menor a solubilidade, menor será a disponibilidade dos microminerais para a forragem. Dessa forma, é preciso sempre analisar os teores de microminerais em associação à análise do $\mathrm{pH}$ do solo. $\mathrm{O} \mathrm{pH}$ médio dos solos neste estudo pode ser considerado próximo à neutralidade, o que resultaria em uma disponibilidade menor dos microminerais para as forragens. Em estudo realizado por Sousa et al. (1980), o pH de solo 6,5 foi suficiente para diminuir a disponibilidade do cobre para as plantas, a ponto de os animais acumularem significativamente menos cobre que os animais criados nos demais tipos de solo com $\mathrm{pH}$ mais ácido.

Apesar de solos com $\mathrm{pH}$ ácido favorecerem disponibilidade de microminerais como cobre, ferro e zinco para plantas, o intervalo de $\mathrm{pH}$ 6,06,5 é o mais favorável para o crescimento das plantas, proporcionando disponibilidade máxima para macronutrientes como nitrogênio, fósforo e enxofre (Faquin, 2005). Nesse aspecto, 
suplementar os animais com microminerais é mais interessante do que acidificar o $\mathrm{pH}$ do solo para favorecer sua disponibilidade para a planta, pois isso prejudica o crescimento vegetal e, consequentemente, gera menor quantidade de forragem.

Em relação ao cobre sérico, verificou-se que os valores obtidos para as espécies caprina e ovina $(13,8$ e $12,2 \mu \mathrm{mol} / \mathrm{L}$, respectivamente) foram ligeiramente superiores aos resultados obtidos por Silva Júnior (2013), que obteve valores médios de $11,5 \mu \mathrm{mol} / \mathrm{L}$ para caprinos e de $10,4 \mu \mathrm{mol} / \mathrm{L}$ para ovinos em estudo desenvolvido na microrregião de Petrolina, com clima semelhante à região alvo do presente estudo. Os valores obtidos por Marques et al. (2011) também foram inferiores, com teores médios de $9,85 \mu \mathrm{mol} / \mathrm{L}$ para ovinos e de $11,37 \mu \mathrm{mol} / \mathrm{L}$ para caprinos, valores esses considerados como deficiência marginal pelos autores. Suttle (2010) considerou que os animais com carência marginal de cobre apresentam valores séricos de cobre entre 3 e $9 \mu \mathrm{mol} / \mathrm{L}$. No presente estudo, não foi constatado nenhum animal com sinais clínicos aparentes de carência de cobre, contrastando com o estudo desenvolvido por Santos et al. (2006), que encontraram valores médios de $12,9 \mu \mathrm{mol} / \mathrm{L}$ em um surto de ataxia enzoótica no Agreste Pernambucano.

A diferença significativa entre os valores médios de ovinos e caprinos, com estes apresentando maiores valores médios, pode ser explicada pelo fato de os caprinos serem criados extensivamente e terem habilidade para encontrar seu alimento de forma mais efetiva que os ovinos. Caprinos são capazes de se alimentarem de plantas que os ovinos não conseguem alcançar e, assim, incluem em sua dieta grande variedade de plantas (Jansen e Burg, 2004), preferindo dicotiledôneas herbáceas e os brotos e folhas de árvores e de arbustos onde se tem maior qualidade, diferentemente dos ovinos, que possuem hábito de pastejo mais baixo, mais rente ao solo, tendo acesso a uma seleção menos variada de alimentos (Araújo Filho et al., 1996).

Ortolani (2002) afirma que fêmeas são mais predispostas ao acúmulo de cobre pela ação do estradiol,o qual pode aumentar a retenção desse micromineral pelo efeito anabólico que torna o organismo mais propenso ao armazenamento de nutrientes. Entretanto, neste estudo, as fêmeas apresentaram valor mais elevado que os machos apenas de cobre sérico, sem apresentar diferença nos teores cúpricos hepáticos, contrariando o postulado por Ortolani (2002). O aumento apenas dos teores séricos em fêmeas pode ser explicado pelo fato de que valores mais elevados de estrógeno aumentam os teores de ceruloplasmina, proteína responsável por conter $80 \%$ do cobre sérico (Fischer, L’Abbé e Giroux, 1990).

Entretanto, ao se analisar o cobre hepático, principal reservatório desse micromineral no organismo, verificou-se que os valores médios para ovinos e caprinos foram de 238 a $220 \mathrm{ppm}$ em níveis superiores quando comparados aos encontrados por Marques et al. (2011) (158ppm para ovinos e 152ppm para caprinos), que consideraram a existência de deficiência inaparente de cobre nestes animais criados na região do Sertão de Pernambuco. Os valores obtidos por Silva Júnior (2013), em estudo realizado na região do São Francisco, em Pernambuco, cujo clima e vegetação são semelhantes aos da região onde este estudo foi realizado, foram próximos aos encontrados neste trabalho, em que ovinos apresentaram valores médios de 248ppm e caprinos, de 245ppm. Animais que desenvolveram quadro clínico de ataxia enzoótica apresentaram valores que variaram de 19 a 140ppm (Santos et al., 2006).

$\mathrm{Na}$ análise do zinco sérico para ovinos e caprinos, foram obtidos valores médios de 28,7 e $28,3 \mu \mathrm{mol} / \mathrm{L}$, respectivamente, valores esses sempre superiores aos considerados na literatura como limites deficientes ou deficientes marginais, conforme citado por Van Niekerk et al. (1990) $(12,2 \mu \mathrm{mol} / \mathrm{L})$ e Suttle (2010) $(10 \mu \mathrm{mol} / \mathrm{L})$. Estudo realizado no Sertão de Pernambuco encontrou valores abaixo do considerado marginal (Marques et al., 2011), no entanto Silva Júnior (2013), em trabalho realizado em condições semelhantes a este trabalho, determinou valores médios dentro da normalidade, mas ainda inferiores aos encontrados no presente trabalho. Os resultados médios obtidos neste trabalho ficaram acima dos intervalos determinados como normais por Suttle (2010), cujo intervalo seria entre 12 e $18 \mu \mathrm{mol} / \mathrm{L}$. Justifica-se esse valor mais elevado de zinco sérico provavelmente pelos altos teores de zinco no solo dessa região (Ribeiro et al., 1999). 
Foi possível verificar que as concentrações de zinco no fígado foram maiores no período chuvoso e compatíveis com os resultados encontrados por outros autores (Antonelli, 2007; Marques et al., 2011; Silva Júnior, 2013). Entretanto, os valores obtidos na época de seca podem ser considerados deficientes tanto para ovinos como para caprinos (Suttle, 2010). Mesmo considerando teores de zinco altos no solo da região, os animais não promoveram um acúmulo muito evidente no fígado no período chuvoso, mostrando até uma ligeira deficiência. Tal fato pode ser explicado pela baixa capacidade de estocar esse microelemento em tecidos, em um estudo realizado com suínos (Miller et al., 1968), apesar da alta concentração do elemento no sangue. De acordo com LópezAlonso et al. (2005), maiores quantidades de zinco hepático estimulam a produção de metalotioneína no fígado, sendo essa proteína responsável pela complexação com o cobre hepático que será excretado pela bile. Minervino (2011) sugeriu que ruminantes com altos teores de cobre hepático passam a acumular zinco no fígado na tentativa de aumentar a excreção do cobre. Como neste trabalho os animais não apresentaram teores hepáticos de cobre elevados, provavelmente não houve estímulo para armazenar zinco nos tecidos.

As concentrações séricas de ferro apresentaram diferença significativa apenas entre os períodos seco e chuvoso $(50$ e $73 \mu \mathrm{mol} / \mathrm{L}$, respectivamente), provavelmente devido ao fato de a fonte de água fornecida aos animais ser distinta nos períodos estudados. Enquanto no período seco os animais recebem água oriunda de poços artesianos, no período chuvoso os animais têm acesso aos barreirais, cuja água é muito mais barrenta, e, como consequência, o animal provavelmente ingere uma quantidade maior de solo, que, neste trabalho, mostrou-se com uma alta disponibilidade de ferro. Esses resultados foram antagônicos ao verificado por Silva Júnior (2013), que encontrou teores de ferro sérico significativamente maiores no período seco para ovinos, justificado por uma maior ingestão de solo ao pastejar de forma mais rasteira quando não há chuvas (Araújo Filho, 1996). Comparados com os de outros autores, os valores encontrados neste trabalho foram muito superiores. Suttle (2010) considera teores acima de $39 \mu \mathrm{mol} / \mathrm{L}$ como excessivos, e Marques et al. (2011) determinaram valores médios de
$35,6 \mu \mathrm{mol} / \mathrm{L}$ para ovinos e de $25 \mu \mathrm{mol} / \mathrm{L}$ para caprinos, comprovando a alta ingestão desse elemento.

Os valores de ferro hepático seguiram o mesmo padrão do ferro sérico, mostrando valores mais elevados na época da chuva devido ao fato de haver alta disponibilidade de ferro no solo da região estudada e de a água ingerida nesta época mais chuvosa conter uma quantidade de solo muito grande. Apesar dos teores elevados de ferro detectados neste experimento, não foram verificados baixos teores de cobre, já que a literatura estabelece o ferro como antagonista do cobre e autores já justificaram a carência de cobre pelo excesso de ferro na dieta (Santos et al., 2006). A inibição do metabolismo do cobre pelo excesso de ferro pode ser atribuída à ação do enxofre em se conjugar com o ferro no rúmen, e, em seguida, ao atingir o meio ácido do abomaso, ocorrer uma dissociação, o que disponibiliza o enxofre a formar uma ligação mais forte com o cobre e, consequentemente, indisponibiliza este último para absorção, conforme a Teoria da Arapuca estabelecida por Suttle (Suttle et al., 1984). Não foram determinadas as concentrações de enxofre neste experimento, mas, devido à não diminuição dos teores de cobre ante os elevados teores de ferro, supôs-se que a quantidade de enxofre presente na dieta era relativamente baixa. Características semelhantes quanto ao fator espécie foram encontradas por Marques et al. (2011), bem como valores superiores ao de Jones et al. (1984), de 138,8 $\pm 17,8 \mathrm{ppm}$.

Quando analisados os resultados de molibdênio sérico, foi possível verificar que houve um aumento significativo no período chuvoso, claramente verificado nos caprinos machos, época em que houve um incremento significativo na quantidade de amostras com valores acima de $0,05 \mu \mathrm{mol} / \mathrm{L}$, determinados, consequentemente, pelo equipamento. Tal variação deve ser explicada pelo aumento da qualidade da forragem com o aumento das chuvas no período. Esses valores foram semelhantes ao encontrado por Silva Júnior (2013) em condições edafoclimáticas semelhantes, e por Pott et al. (1999), que consideraram valores entre $0,10 \mathrm{e}$ $0,20 \mu \mathrm{mol} / \mathrm{L}$, e próximos ao de Marques et al. (2011), com valor médio de $0,29 \mu \mathrm{mol} / \mathrm{L}$. 
Os teores de molibdênio no fígado encontravamse próximos aos determinados por Silva Júnior (2013) e Van Ryssen e Stielau (1980), com $2,8 \mathrm{ppm}$, mas inferiores ao resultado médio de 3,80ppm encontrado por Antonelli (2007), e bem inferiores aos de Marques et al. (2011) e Jones et al. (1984), com 7,4ppm e 5,88ppm, respectivamente. A presença de maior quantidade de enxofre na dieta pode diminuir a absorção de molibdênio ou aumentar sua excreção (Suttle, 2010), o que pode resultar em menores teores deste micromineral em órgãos estoque. A presença de teores de cobre mais elevados em dietas fibrosas com alto teor de enxofre estimula a formação de tiomolibdatos, tornando o molibdênio ingerido indisponível para absorção pelo organismo (Suttle, 2010), sendo verificada uma relação linear do aumento de enxofre na dieta com a diminuição da concentração hepática de molibdênio (Van Ryssen e Stielau, 1980). Conti (2014) verificou um efeito significativo na interação entre cobre, enxofre e molibdênio. Entretanto, se houvesse excesso de enxofre na dieta, os teores elevados de ferro influenciariam na diminuição da concentração de cobre, fato esse que não ocorreu.

\section{CONCLUSÕES}

Apenas a análise de microminerais no solo não é suficiente para predizer se ovinos e caprinos apresentam ou não carência de cobre. Os teores médios obtidos para cobre em caprinos e ovinos criados nos municípios de Juazeiro e Casa Nova indicam que não há carência de cobre primária ou secundária. Apesar dos altos teores de ferro, supõe-se que o acúmulo de cobre hepático nessa região não é baixo devido a menores teores de enxofre na dieta.

\section{AGRADECIMENTOS}

Os autores agradecem à Capes, pela bolsa de mestrado concedida ao primeiro autor no Programa de Pós-Graduação em Ciência Animal da Univasf.

\section{REFERÊNCIAS}

ANTONELLI, A.C. Avaliação do uso de um sal mineral rico em molibdênio na prevenção da intoxicação cúprica acumulativa em ovinos. 2007. 122f. Tese (Doutorado) - Faculdade de Medicina Veterinária e Zootecnia, Universidade de São Paulo, São Paulo, SP.

ARAÚJO FILHO, J.A.; SOUSA, F.B.; CARVALHO, F.C. Composição botânica e química da dieta de ovinos e caprinos em pastoreio combinado na região dos Inhamuns, Ceará. Rev. Soc. Bras. Zootec., v.25, p.383- 395, 1996.

BELCHIOR, E.B.; SOUZA, J.D.F.; ALMEIDA, H.C.G. et al. A importância do perfil socioeconômico de criadores de ovinos de corte na elaboração de políticas públicas. In: CONGRESSO DA SOCIEDADE BRASILEIRA DE ECONOMIA, ADMINISTRAÇÃO E SOCIOLOGIA RURAL, 52., 2014, Goiânia. Anais...Goiânia: SOBER, 2014. p.1-17.

CAMARGO, O.A.; VALADARES, J.M.A.S.; DECHEN, A.R. Efeitos do $\mathrm{pH}$ e da incubação na extração do manganês, zinco, cobre e ferro do solo. Rev. Bras. Cienc. Solo, v.6, p.83-88, 1982.

CAPRINOCULTURA na Bahia. Brasília: CONAB, 2006. 13p.

CONTI, R.M.C. Efeito de fontes orgânicas de cobre e enxofre sobre a interação cobre, molibdênio e enxofre na alimentação de ovinos. 2014. 84f. Tese (Doutorado) - Faculdade de Zootecnia e Engenharia de Alimentos da Universidade de São Paulo, Pirassununga, SP.

FAQUIN, V. Nutrição mineral de plantas. Lavras: UFLA/FAEPE, 2005. 186p.

FISCHER, P.W.F.; L'ABBÉ, M.R.; GIROUX, A. Effects of age, smoking, drinking, exercise and estrogen use on indices of copper status in healthy adults. Nutr.Res., v.10, p.1081-1090, 1990.

JANSEN, C.; BURG, K.V. Criação de cabras nas regiões tropicais, Wageningen: Fundação Agromisa, 2004. 91p.

JONES, H.B.; GOONERATNE, S.R.; HOWELL, J.M. X-ray microanalysis of liver and kidney in copper loaded sheep with and without thiomolybdate administration. Res. Vet. Sci., v.37, p.273-282, 1984. 
LÓPEZ-ALONSO, M; PRIETO, F.; MIRANDA, M. et al. The role of metallothionein and zinc in hepatic copper accumulation in cattle. Vet. J., v.169, p.262-267, 2005.

MARQUES, A.V.S.; SOARES, P.C.; RIETCORREA, F. et al. Teores séricos e hepáticos de cobre, ferro, molibdênio e zinco em ovinos e caprinos no estado de Pernambuco. Pesqui. Vet. Bras., v.31, p.398-406, 2011.

McDOWELL, L.R. Minerais para ruminantes sob pastejo em regiões tropicais, enfatizando o Brasil. 3.ed. Gainesville: University of Florida, 1999. 292p.

MILLER， E.R.; LUECKE， R.W.; ULLREY, D.E. et al. Biochemical, skeletal and allometric changes due to zinc deficiency in the baby pig. $J$. Nutr., v.95, p.278-286, 1968.

MINERVINO, A.H.H. Avaliação de crescentes teores de zinco dietético no metabolismo de cobre e na prevenção de intoxicação cúprica em ovinos. 2011. 69f. Tese (Doutorado em Medicina Veterinária) - Faculdade de Medicina Veterinária e Zootecnia da Universidade de São Paulo, São Paulo, SP.

ORTOLANI, E. L. Macro e microelementos. In: SPINOSA, H.S.; GÓRNIAK, S.L.; BERNARDI, M.M. Farmacologia aplicada à medicina veterinária. 3.ed. Rio de Janeiro: Guanabara Koogan, 2002. p.641-651.

PAGE, A.L.; MILLER, R.H.; KEENEY, D.R. Methods of soil analysis: part 1: Physical and mineralogical methods. 2.ed. Madison: ASA, 1986. 1188p.

POTT, E.B.; HENRY, P.R.; ZANETTI, M.A. et al.. Effetcs of hight molybdenum concentration and duration of feeding time on molybdenum and copper metabolism in sheep. Anim. Feed Sci. Technol., v.79, p.93-105, 1999.

RIBEIRO, A.C.; GUIMARÃES, P.T.G.; ALVAREZ, V.H. Recomendações para o uso de corretivos e fertilizantes em Minas Gerais: 5a aproximação. Viçosa: SBCS, 1999. 359 p.
SANTOS, N.V.M.; SARKIS, J.E.S.; GUERRA, J.L. et al. Avaliação epidemiológica, clínica, anatomopatológica e etiológica de surtos de ataxia em cabritos e cordeiros. Ciênc. Rural, v.36, p.1207-1213, 2006.

SILVA, F.C. Manual de analises químicas de solo, plantas e fertilizantes. 2.ed. Brasília: Embrapa, 2009. p.23-55.

SILVA JÚNIOR, S.S. Determinação dos teores de cobre e seus principais antagonistas em ovinos e caprinos criados na microrregião de Petrolina em Pernambuco, 2013. 92f. Dissertação (Mestrado) - Universidade Federal do Vale do São Francisco, Petrolina, PE.

SOUSA, J.C.; CONRAD, J.H.; McDOWELL, L.R. et al. Inter-relações entre minerais no solo, forrageiras e tecido animal. 2. Cobre e molibdênio. Pesqui. Agropecu. Bras., v.15, p.335-341, 1980.

SUTTLE, N.F.; ABRAHAMS, P.; THORNTON, I. The role of a soil $\times$ dietary sulphur interaction in the impairment of copper absorption by ingested soil in sheep. J. Agr. Sci., v.103, p.8186,1984 .

SUTTLE, N.F. Mineral nutrition of livestock. 4.ed. Oxforshire: CABI, 2010. 587p.

TOKARNIA, C.H.; DÖBEREINER, J.; MORAES, S.S.; PEIXOTO, P.V. Deficiências e desequilíbrios minerais em bovinos e ovinosrevisão dos estudos realizados no Brasil de 1987 a 1998. Pesqui. Vet. Bras., v.19, p.47-62, 1999.

TOKARNIA, C.H.; DÖBEREINER, J.; PEIXOTO, P.V. Deficiências minerais em animais de fazenda, principalmente bovinos. Pesqui. Vet. Bras., v.20, p.127-138, 2000.

VAN NIEKERK, F.E.; CLOETE, S.W.P.; BARNARD, S.A. et al. Plasma copper, zinc and blood selenium concentrations of sheep, goats and cattle. S. Afr. J. Anim. Sci., v.20, p.144-147, 1990.

VAN RYSSEN, J.B.J.; STIELAU, W.J. The effect of various levels of dietary copper and molybdenum on copper and molybdenum metabolism in sheep. S. Afr. J. Anim. Sci., v.10, p.37-47, 1980 . 